Table 1

The Mean Unconditioned Vasomotor Response of $47 \mathrm{Ss}$ to 1 Sec of $100 \mathrm{~dB}$ White Noise Measured in $\mathrm{mm}$ of Pen Deflection for Two Trial Blocks

\begin{tabular}{|c|c|c|c|c|c|c|c|c|c|c|c|c|c|}
\hline Block & 1 & 2 & 3 & 4 & 5 & 6 & 7 & 8 & 9 & 10 & 11 & 12 & 13 \\
\hline $\mathrm{m}$ & 2.9 & 1.3 & 1.6 & 0.5 & 0.8 & -0.1 & 0.4 & -0.1 & 0.8 & 0.3 & 0.0 & 0.7 & -0.1 \\
\hline
\end{tabular}

to BLOSSOM was close to zero.

The mean VR to the first CS was $.6 \mathrm{~mm}$, the mean VR to the control word preceding the last CS was $-.3 \mathrm{~mm}$, and the mean VR to the final CS was $.2 \mathrm{~mm}$. Since all readings were taken to the nearest millimeter, mean differences of less than $1 \mathrm{~mm}$ could not be regarded as reliable, and no statistical tests seemed warranted. Thus, the data provided no evidence for semantic conditioning or for semantic generalization. Although 45 of the 47 Ss indicated on a postexperimental semantic differential that CAR was QUITE UNPLEASANT or VERY UNPLEASANT (control Ss had rated CAR as SLIGHTLY PLEASANT), the VR to CAR ( $M=0 \mathrm{~mm})$ was very similar to the VR to the preceding neutral word, SONG $(\mathrm{M}=.6 \mathrm{~mm})$. Although the OR to both BLOSSOM and to US1 was larger for females than for males, the differences were not statistically reliable $[F(1,45)=1.44, p>.05]$. No differential response patterns emerged for $S s$ who provided high, medium, or low scores on the anxiety scale. Since 45 of the 47 Ss who provided data for the present experiment had indicated on a postexperimental questionnaire that they were aware of the contingencies of the experiment, and since 46 of the 47 Ss had exhibited classical conditioning of the GSR to the verbal concepts employed, the failure to find evidence for classical conditioning or generalization cast doubt upon the usefulness of the VR as an index of semantic conditioning or generalization.

\section{DISCUSSION}

The scoring of the polygraph records presented considerable difficulty, despite the fact that prolonged training of the readers finally resulted in excellent reliability. Three separate scoring rules were initially adopted, and the first 12 records were scored according to the three separate systems. Although there was variation in individual scores as a function of scoring rule, the general results did not vary. In some cases, there was a definite constriction or dilation that could reliably be identified as the VR, but, in other cases, there were multiple changes in direction that could be interpreted as a series of responses or as a single biphasic response. The scoring rule that was finally adopted to define the VR was followed'by the readers, despite the fact that following the rule occasionally resulted in scores that seemed inconsistent with the general impression derived from visual inspection of the polygraph record.
Although the first verbal stimulus and the first four USs produced vasodilations, there was no evidence that these responses were replaced by vasoconstrictions following repeated stimulations. Thus, the predicted switch from ORs to DRs failed to occur, and there was no conclusive evidence that DRs were manifested in the cephalic vasomotor response. Although the data of an additional 152 Ss were available, there seemed no likelihood that the essential results would have been altered on the basis of the inclusion of additional data. These results were quite similar to those reported by Raskin and his colleagues (Raskin et al, in press). On the basis of these data, it may be concluded that the forehead VR, under the conditions of the present research, fails to provide an adequate index for reliably differentiating ORs from DRs or an adequate index for assessing semantic conditioning or generalization.

\section{REFERENCES}

BENDIG, A. W. The development of a short form of the MAS. Joumal of Consulting Psychology, $1956,20,384$

BOUSFIELD, W. A., COHEN, B. H. WHITMARSH, C. A., \& KINCAID, W. D Connecticut free associational norms. Technical Report No. 35, University of Connecticut, Contract Nonr 631(00), Office of Naval Research, 1961.

BROTSKY, S. J. Classical conditioning of the

\section{DAVID J. KING, State University College, Oswego, N.Y. 13126}

Eighty Ss were divided among eight treatment groups in a 2 by 2 by 2 design. The main effects were delayed auditory feedback is immediate auditory feedback $(D A F$ vs $I A F)$ learning of connected discourse, $D A F$ us $I A F$ recall of the previously read material, and sex. Accuracy of recall was influenced only by the $D A F$ vs IAF learning condition. DAF apparently influences only the learning and not the recall processes. Implications of these results were also examined regarding the question of the influence of distractability in producing the DAF-induced memory loss. galvanic skin response to verbal concepts. Journal of Experimental Psychology, 1968, 76, 244-253.

BROTSKY, S. J., RASKIN, D.C., \& MALTZMAN, I. The orienting reaction, semantic conditioning, and generalization of a vasomotor response. Paper read at Western Psychological Association, Santa Monica, Calif., 1963.

LURIA, A. R., \& VINOGRADOVA, O. S. An objective investigation of the dynamics of semantic systems. British Journal of Psychology, 1959, 50, 89-105.

MALTZMAN, I., \& RASKIN, D. C. The effects of individual differences in the orienting reflex on conditioning and complex processes. Journal of Experimental Research in Personality, 1965, 1 , 1-16.

RASKIN, D. C. Semantic conditioning and generalization of autonomic responses. Joumal of Experimental Psychology, 1969, 79, 69-76.

RASKIN, D, C., KOTSES, H., \& BEVER, J. Cephalic vasomotor and heart rate measures of orienting and defensive reflexes. Psychophysiology, in press.

SOKOLOV, E. N. Perception of the conditioned reflex. New York: Macmillan, 1963.

\section{NOTES}

1. This report is based on a $\mathrm{PhD}$ dissertation submitted to the University of California, Los Angeles. Facilities and partial support were provided by USPHS Grant No. MH-04684-02; Irving Maltzman was the principal investigator. The report was written during the writer's tenure as NIH Special Fellow in Human Development, 1968, Harvard University. Thanks are due to Irving Maltzman and to David Raskin for assistance and encouragement, and to Nancy Black and to Janet Morgan who helped with data analy sis.

2. Circular zinc electrodes were attached to the center of Ss' palms with plastic clips to pick up GSR activity. Results based on GSR data, as well as on verbal reports for $200 \mathrm{Ss}$, were reported in full in an earlier paper (Brotsky, 1968). Fortyeight Ss received 15 or more CS-US trials, but since the VRs of one $S$ were unreadable due to equipment failure, the present report is based on data for $47 \mathrm{Ss}$.

\title{
The retention of connected discourse presented and recalled under delayed auditory feedback
}

The reliable experimental production of forgetting of connected discourse has been most difficult. Despite reports of success (Slamecka, 1960a, b), the utilization of reasonable everyday learning materials and procedures frequently results in negative findings (King \& Tannenbaum, 1963). There seems to be a possibility that the technique of delayed auditory feedback may prove to be a tool capable of producing forgetting of connected discourse. Several experiments (King, 1963; King \& Walker, 1965) have demonstrated poorer retention of connected discourse when the material is practiced under DAF as contrasted with the control condition of IAF.

Recent experiments have also shown 
that the memory-loss effect does not occur when the learning material consists of unconnected material (Williams \& Frincke, 1969; Murdock, 1967). Ss, reading connected discourse under DAF and then being asked to recall the material, frequently comment about the distraction produced by DAF. Not infrequently, Ss suggest that their inability to remember the material is due to their having had to concentrate on reading the words rather than on what the words said. Two lines of investigation suggest that the immediate memory loss is not due to some type of distraction effect. First, the 24-h delayed recall of material presented under DAF produces a substantial increase in the amount of recall relative to immediate recall (King \& Wolf, 1965; King \& Dodge, 1965). Second, there is no significant difference in immediate retention whether or not Ss are told that they will be asked to recall the material (King, 1963, 1968a, b).

The present study extends the study of the influence of DAF vs IAF conditions directly to the recall process in addition to the learning process. Implications of the results for the problem of distraction will also be examined.

\section{METHOD}

The Ss were 80 students, 40 male and 40 female, who were enrolled in the introductory psychology course at State University College at Oswego.

The learning material was a previously published (King \& Walker, 1965) 166-word-long short story that dealt with increased use of the oceans and seas.

Lafayette Instrument Company's Model 775a was the DAF apparatus. The recalls were recorded and transcribed from a Wollensak recorder. Reading and recall times were obtained with the use of second stop clocks (Lafayette Model 5661-ADW).

Each $S$ was fitted to the DAF apparatus and, following a brief conversation, was asked to read the learning material, Immediately following the reading, each S was then asked to orally recall the story, as close to the original as possible. Unlimited, but measured, time was given for both the reading and the recall tasks. Within the limits of sex and numerical balance, Ss were assigned at random to one of eight basic treatment groups. The general desígn of the study was a 2 by 2 by 2 , the dimensions representing sex, DAF vs IAF reading, and DAF vs IAF recall. Those Ss reading and/or recalling the material under DAF were given the standard $0.2 \mathrm{sec}$ of delay.

The recalls were transcribed and scored for accuracy of recall by counting the total number of words and the total number of three-word sequences (King, 1968a,b). The overall accuracy score represented an arithmetic combination of words and sequences.

\section{RESULTS}

The DAF vs IAF effect had a significant influence on reading time $(F=16.03$, $\mathrm{p}<.001$ ), with the mean reading time, in seconds, for the IAF reading of 65.6 and a time of 90.3 for the DAF reading. There was a weaker, but still significant, influence of method of recall on reading time $(F=7.21, p<.01)$, with the mean reading times for the IAF and DAF classifications of 77.4 and 61.0, respectively. Analysis of the recall-time data produced two significant effects. Recall time was significantly influenced by the method of reading $(F=16.24, p<.001)$, with the mean recall time for IAF reading of 61.3 and for DAF of 41.5. There was also a weaker, but significant, interaction effect $(F=7.28, p<.01)$ between reading and recall.

The accuracy of recall was influenced only by the method of reading (i.e., DAF vs IAF reading, $F=19.25, p<.001$ ). The mean accuracy of recall for IAF reading was 58.25 , while the corresponding DAF mean was 33.25 .

\section{DISCUSSION}

The slowing-down effect of DAF on reading time was as expected, being consistent with prior findings, and need not be further discussed. The finding of a weaker effect of method of recall (DAF vs IAF) on reading rate during learning makes little sense. It could be attributable to chance assignment of $S s$ with different reading rates or to possible $\mathrm{E}$ bias. The recall-time data are slightly more interesting. The apparently surprising result that recall time is primarily influenced by method of reading (DAF vs IAF) is simply due to the influence that the two methods have on retention. DAF reading produces a much smaller recall than does IAF reading and can then be recalled in a much shorter time. The lack of an overall significant effect of method of recall on recall time is the result of the interaction effect between recall and reading. The mean recall time (in seconds) for those who learned under IAF reading was 51.1 for IAF recall but 71.6 for DAF recall. Thus, recalling under DAF conditions does produce the usual slowing of speech. On thy other hand, those that read under DAF presentation had a mean recall time of 44.6 for the IAF recall and a mean of 38.4 for the DAF recall. The influence of DAF vs IAF reading produced DAF-IAF recall times in enough of a different direction to cancel out a significant overall effect.

The major finding of this study is the lack of influence of DAF (vs IAF) during the recall of connected discourse. The significant effect of DAF on the learning of connecte; discourse is consistent with prior studies. Whatever the differences may be between the processes underlying the learning and the recall of connected discourse, DAF apparently influences only the learning and not the recall processes.

The results of this study also relate to the question of distractability as the cause of memory loss under DAF learning. It is, of course, impossible to separate the distraction effect from DAF, and the present study does not pretend to do so. On the other hand, if distraction is such a powerful influence, it seems strange that it was not influential in producing a decrease in retention when recall was under DAF conditions. The above results, especially when coupled with the enhancement of delayed DAF recall and the lack of instructional effects, give further support to the idea that memory loss for connected discourse practiced under DAF is not due to distraction.

\section{REFERENCES}

KING, D. J. Immediate memory of connected meaningful material practiced under delayed auditory feedback. Psychological Reports, 1963, 13, 91-96.

KING, D. J. Replication study of two unusual findings on the influence of delayed auditory feedback on retention. Perceptual \& Motor Skills, 1968a, 26, 559-562.

KING, D. J. Retention of connected meaningful materiad as a function of modes of presentation and recall. Joumal of Experimental Psychology, 1968b, 77 676-683.

KING, D. J., \& DODGE, A. The influence of oral recall on immediate and delayed memory for meaningful material practiced under delayed auditory feedback. Perceptual \& Motor Skills, $1965,21,483-488$.

KING, D. J., \& TANNENBAUM, S. Comparison of two procedures in the study of retroactive interference in connected meaningful material. Journal of Experimental Psychology, 1963, $65,420-421$.

KING, D. J., \& WALKER, H. J. The effect of prompting on the immediate recall of meaningful material practiced under delayed auditory feedback. Perceptual \& Motor Skills, $1965,21,383-388$.

KING, D. J., \& WOLF, S. The influence of delayed anditory feedback on immediate and delayed memory. Journal of Psychology, $1965,59,131-139$.

MURDOCK, $B$. The effects of noise and delayed auditory feedback on short-term memory. Journal of Verbal Learning \& Verbal Behavior. $1967,6,737-743$.

SLAMECKA, N. J. Retroactive inhibition of connected discourse as a function of practice level. Joumal of Experimental Psychology, 1960\%, 59, 104-108.

SLAMECKA, N. J. Retroactive inhibition of connected discourse as a function of similarity of topic. Journal of Experimental Psychology, 1960b, 60, 245-249.

WLLIAMS, C. H. D., \& FRINCKE, G. Effects of delayed auditory feedback on immediate and delayed recall and recognition. Joumal of Experimental Psychology, 1968, 76, 273-276. 